\section{Cells and the single} author

\section{J.G. Edwards}

Cell Biology, 2nd Edn.

By Gerald Karp.

McGraw-Hill: 1984. Pp.896.

$\$ 35.95$, £29.95.

Cells and Organelles, 3rd Edn.

By Eric Holtzman and Alex B. Novikoff. Holt Saunders/Holt, Rinehart \&

Winston: 1984. Pp.660. £24.95, \$32.95.

THE acclaim which greeted the publication of Molecular Biology of the Cell, by Bruce Alberts and five other authors (Garland, 1983), was not solely a response to the excellence of its parts. As Joseph Gall pointed out in his review (Nature 302, 637; 1983), the inclusion of material on development, the immune and nervous systems and special features of plants, pointed to ways in which the teaching of biology at the cellular and molecular levels might be better integrated. In comparison, the narrower horizons of earlier textbooks may seem to do less than justice to the essential unity of modern biology, so one looks at their new editions for compensatory virtues.

Karp's book shares with Alberts's a much stronger component of molecular genetics than used to be found in texts entitled Cell Biology, but despite its new cover photograph of a myogenic clone still lacks Alberts's strong foray into developmental biology. Where both Karp and Alberts cover the same ground, however, the former more often manages to give some insight into experimental origins. For example, Alberts will tell you how many ribosomal genes there are in a Xenopus oocyte, but not about the anucleolate mutant; that allolactose is the real inducer of the lactose proteins in $E$. coli, but not about the diploids which helped unravel the system. Karp sometimes also has the edge in significant details (not just on matters such as oncogenes, where the passage of two years naturally makes all the difference).

In most areas with which I am familiar the reliability seems high, although I am unhappy about the way in which Karp presents the Hayflick phenomenon, both by discussion and juxtaposition, as the result of defective cellular processes. A balanced account would surely include the idea of programmed cell-death, and thus make better sense of immortalizing mutations. Karp's micrographs and diagrams (the latter now in two colours) are excellent. The whole is an impressive achievement, which runs Alberts much closer than I had imagined possible and will strongly tempt those of us who share the author's view of the importance of experimental history for current understanding.

The shorter Cells and Organelles is closer in content to a traditional cytology textbook, and much gentler with the molecular aspects. Controversial areas get balanced, essay-like discussion and there are virtues of a reflective kind. You have to look in Part III of Alberts to understand Karp's cover picture, but only Holtzman and Novikoff point out that this revelation of the route to multinuclearity was one of the early triumphs of cell culture. Small unreliabilities disturb confidence, however: a diagram of skeletal muscle in which the muscle fibres are drawn to look like fibrils; another of a hepatocyte with empty space labelled for a microfilament; EGF named epithelial growth factor; pyruvate produced anaerobically from glucose. In the review copy a number of micrographs are much too dingy for clarity and impact, and some are patchily unsharp.

\section{DNA in sound and vision}

\section{E.J. Wood}

The Techniques in Genetic Engineering

Video Library.*

Series editor R. Williamson.

IRL Press: 1985. PAL in VHS and

Betamax, f85, \$170 each tape, £640,

$\$ 1,280$ the set. Supplementary charge for $P A L$ in U-Matic and NTSC and SECAM standards conversions.

LAST year I reviewed the first videotape in this series (Nature 309, 566; 1984). Now that the whole series is available, how do the programmes live up to the initial promise of that first tape?

Each of the seven subsequent programmes concentrates on a specific technique or a limited area, and lasts 20-30 minutes. After the introduction of the presenter ("an expert in this field") by Professor Williamson, there is a brief and generally clear account by the expert of why a particular technique is of value, and usually some graphics are used to demonstrate in detail how DNA etc. is cut up and manipulated. These individuals mostly do not look directly at the camera, which I found somewhat annoying, while the level of background noise in some of the sequences is unduly obtrusive at times. These sections move fairly rapidly and would not easily be absorbed by the student at the first sitting. But then the video can be "stop-framed" or replayed, until the details are clear. The graphics themselves are quite well done, although they cannot

* 1. Nucleic Acids Techniques - An Overview; 2. Gene Analysis and Southern Blotting; 3. DNA Sequencing Using MI3;4. Gene Libraries; 5. Expression of Cloned Genes; 6. Oligonucleotides - Synthesis and Use; 7. In Vitro Mutagenesis and Use; 8. Microdissection and Microcloning.
A reviewer should perhaps be wary of laying emphasis on how a textbook handles his own small favourite corner. Nevertheless, the time has surely come for better treatment than can be found in any of these volumes (including, surprisingly, Alberts) of the real progress which has been made towards identification of the molecules which join cells together. If any reader is busy revising another textbook, or wants to know about this topic for other reasons, my advice is to ignore most of the secondary literature, and give due attention to the strategy first adopted by Gerisch and also put to such good effect by Gerald Edelman and others.

J.G. Edwards is a Senior Lecturer in the Department of Cell Biology, University of Glasgow.

be said to use animation to its fullest extent, at least in the earlier tapes.

The tapes can be viewed in any order, although most people are likely to do cDNA cloning first. Several times demonstrations are repeated - for example, preparing DNA by ethanol precipitation, making cells competent by adding $\mathrm{CaCl}_{2}$, electrophoresis on slab gels and baking nitrocellulose filters in an oven. Maybe each is appropriate at that particular juncture, but given the cost of the whole set of programmes so many repeats were perhaps unnecessary.

A more general, but more serious point, is that in places too much detail is given about a technique, so that the underlying message becomes obscured; for example, it cannot really matter very much that the buffer reservoir of a slab-gel apparatus holds 0.8 litre of buffer, and excessive attention is paid to the disposal of radioactive pipette tips. Still, the demonstrations of techniques are indeed on the whole of high quality: the only exception to this is the demonstration of the microforge, which is poor but probably technically difficult to show.

In order to benefit fully from the tapes students would have to work through each a number of times, stopping and starting as necessary, probably writing down the sequences in the graphics. At this level I feel they would learn quite well from the tapes alone. The prize for the best and clearest tape goes to Oligonucleotides, closely followed by Microdissection and Microcloning, while the worst missed opportunity was in animating nick translation which could have been done so much better. But this must have been a difficult project to mastermind, especially to judge how much to put in and in what detail, and overall the tapes do succeed in their aim of being a "self-paced teaching aid"'.

E.J. Wood is a Senior Lecturer in the Department of Biochemistry, University of Leeds. 